\title{
Cinética da degradação ruminal dos carboidratos de quatro gramíneas tropicais em diferentes idades de corte e doses de adubação nitrogenada: Técnica de produção de gases
}

\author{
Edenio Detmann ${ }^{1}$, José Fernando Coelho da Silva ${ }^{2}$, Hernán Maldonado Vásquez ${ }^{2}$, Lara \\ Toledo Henriques ${ }^{3}$, Ismail Ramalho Haddade ${ }^{4}$
}

\footnotetext{
${ }^{1}$ Departamento de Zootecnia, Universidade Federal de Viçosa, Viçosa-MG, 36570-000. Bolsista CNPq

2 Centro de Ciências e Tecnologias Agropecuárias, UENF. Bolsista CNPq.

3 Pós-Doutorando, Departamento de Zootecnia, UFV. Bolsista Capes.

${ }^{4}$ Escola Agrotécnica Federal de Santa Teresa, EAFST.
}

RESUMO - Objetivou-se neste experimento avaliar a cinética de degradação ruminal dos capins setária (Setaria anceps Stapf), hemarthria (Hemarthria altissima [Poir] Stapf. \& Hubbard), angola (Brachiaria purpurascens [Raddi] Henr.) e acroceres (Acroceras macrum Stapf.) adubados com 0, 100, 200, $300 \mathrm{ou} 400 \mathrm{~kg}$ de N/ha e colhidos aos 28, 42, 56 ou 70 dias de idade. Os resultados foram avaliados por intermédio de análise de fatores. Após redução e avaliação da variação conjunta total das variáveis, optou-se pela adoção de três fatores, que englobaram $86,4 \%$ da variação total: o primeiro fator (Fator 1) associou-se ao volume de gás oriundo das frações de lenta e de rápida degradação e à taxa de degradação da fração rapidamente degradável $\left(\mathrm{Vf}_{1}, \mathrm{Vf}_{2} \mathrm{e} \mathrm{k}_{2}\right)$; o segundo fator (Fator 2) associou-se à taxa de degradação de lenta digestão e à latência $\left(\mathrm{k}_{1} \mathrm{e} \mathrm{L}\right)$; e o terceiro fator (Fator 3), por sua vez, associou-se à digestibilidade in vitro da matéria seca (DIVMS). Os parâmetros da cinética de degradação foram influenciados pelas idades de corte. A digestibilidade in vitro da matéria seca reduziu com o avançar da idade das plantas. A adubação nitrogenada não promoveu respostas evidentes nos parâmetros avaliados. O capim-hemarthria se destacou dos demais em virtude de maior digestibilidade.

Palavras-chave: capim-acroceres, capim-angola, capim-hemarthria, capim-setária, produção de gás, taxa de degradação

\section{Kinetic parameters of carbohydrates ruminal degradation of four tropical grasses in different cutting ages and nitrogen fertilizer levels}

\begin{abstract}
The objective of this experiment was to evaluate the effects of levels 0, 100, 200, 300 and $400 \mathrm{~kg}$ of nitrogen/ha and cutting ages of 28, 42, 56 and 70 days on the kinetic parameters of ruminal degradation of carbohydrate of the following tropical forages: Setaria grass (Setaria anceps Stapf), Limpo grass (Hemarthria altissima [Poir] Stapf. \& Hubbard), California grass (Brachiaria purpurascens [Raddi] Henr.) and Nilo grass (Acroceras macrum Stpaf). The results were submitted to a factor analysis. After reduction and evaluation of the combined variation from the total variables, three factors comprising $86.44 \%$ of the total variation were considered, where the first factor (Factor 1) was strongly associated with the gas volume of substrates of slow and rapid digestion, as well as the fractional rate of substrate of rapid degradation $\left(\mathrm{Vf}_{1}, \mathrm{Vf}_{2}\right.$ and $\mathrm{k}_{2}$ ). The second factor (Factor 2) was associated to the fractional degradation rate of the slow degradable substrate and lag phase $\left(\mathrm{k}_{1}\right.$ and $\mathrm{L}$ ) and the third factor (Factor 3) was related to the in vitro dry matter digestibility (IVDMD). Cutting age had an effect on the grass kinetics, where the growth age resulted on reduced IVDMD. No significant responses of the supply of nitrogen fertilizer in relation to the parameters analyzed were found. Due to its high digestibility, the Limpo grass demonstrated to have an outstanding performance when compared to the other grasses.
\end{abstract}

Key Words: California grass, degradation rate, gas production, Limpo grass, Nilo grass, Setaria grass

\section{Introdução}

Considerando que o valor nutritivo das plantas forrageiras pode ser influenciado por práticas de manejo, técnicas têm sido desenvolvidas para permitir que estas plantas expressem todo o seu potencial agronômico de produção e resultem em maior desempenho animal. Freqüências de corte (ou pastejo) e níveis de adubação nitrogenada têm apresentado boas respostas, principalmente no valor nutritivo (Pinto et al., 1994).

Os capins setária (Setaria anceps Stapf.), hemarthria (Hemarthria altissima [Poir] Stapf. \& Hubbard), angola 
(Brachiaria purpurascens [Raddi] Henr.) e acroceres (Acroceras macrum Stapf.) são plantas perenes originárias da África, com grande facilidade de adaptação a regiões de clima tropical e subtropical. Além disso, apresentam grande resistência às secas, requerem solos de média fertilidade, demonstram boa resposta à fertilização e podem atingir produções anuais, como o capim-angola, de até 60 t de massa verde/ha (Silva, 20003). Contudo, resultados concretos sobre a produtividade dessas espécies em situações de variação no manejo e na fertilização são ainda escassas em condições brasileiras.

A avaliação de forrageiras tem grande valor prático na alimentação de ruminantes. Como primeiro passo para essa avaliação, foram inicialmente propostos sistemas que propiciam a obtenção de estimativas da digestibilidade (Mott \& Moore, 1969). Vários métodos têm sido desenvolvidos com este propósito, entre eles, o obtido por mensurações gravimétricas que utilizam tempo único de incubação, como o método da digestibilidade in vitro, proposto por Tilley \& Terry (1963).

Contudo, para que se obtenham estimativas mais acuradas dos parâmetros digestivos dos alimentos, é necessário obter estimativas das taxas de degradação ruminal destes alimentos. Estas taxas, por sua vez, são inicialmente obtidas por técnicas gravimétricas, que apresentam limitações inerentes por serem laboriosas, apresentarem baixa repetibilidade e não permitirem a obtenção das taxas de digestão da fração solúvel dos alimentos, visto que as alterações nos pesos das amostras incubadas nos tempos iniciais de fermentação são relativamente pequenas, o que dificulta suas mensurações (Schofield \& Pell, 1995). Por outro lado, técnicas de enfoque metabólico, que se baseiam não na mensuração do substrato nãodegradado, mas nos produtos finais da degradação, foram desenvolvidas com o propósito de reduzir essas limitações. Entre estas técnicas, a de produção cumulativa de gases é uma das técnicas metabólicas mais utilizadas para estimar taxas de degradação ruminal.

As vantagens em utilizar a técnica de produção de gás consistem primeiramente em caracterizar de forma mais adequada as particularidades do alimento, como a contribuição dos carboidratos solúveis, seguida pela rapidez e uniformidade físico-química do meio (Malafaia et al., 1998).

Neste sentido, objetivou-se avaliar os efeitos de diversas doses de nitrogênio associadas a diferentes idades de corte sobre os parâmetros da cinética de degradação ruminal das frações de carboidratos fibrosos e não-fibrosos e sobre a degradação in vitro da matéria seca dos capins setária, hemarthria, angola e acroceres cultivados na região Norte Fluminense.

\section{Material e Métodos}

Este experimento foi conduzido no Laboratório de Zootecnia e Nutrição Animal (LZNA), no Centro de Ciências e Tecnologias Agropecuárias (CCTA), e no setor de Forragicultura, localizado nas dependências da Escola Estadual Agrícola Antônio Sarlo, ambos pertencentes à Universidade Estadual do Norte Fluminense (UENF), Campos dos Goytacazes, Rio de Janeiro, entre outubro de 2000 e junho de 2001. Os capins setária, hemarthria, angola e acroceres foram adubados com $0,100,200,300 \mathrm{ou} 400 \mathrm{~kg}$ de N/ha na forma de sulfato de amônio e colhidos aos 28 , 42, 56 e 70 dias de idade após o corte de uniformização.

As gramíneas foram cultivadas em área de baixada (total de $2.100 \mathrm{~m}^{2}$ ), com parcelas que mediam $150 \mathrm{~m}^{2}$ com $1,00 \mathrm{~m}$ de espaçamento, subparcelas de $30 \mathrm{~m}^{2}$ e subsubparcelas de $6 \mathrm{~m}^{2}$. Efetuou-se adubação de correção do solo em outubro de 2000, antes do plantio das gramíneas, conforme resultado de análise de solo, corrigindo-se a acidez por efeito de calagem baseada na elevação de saturação de bases a 50\%, de acordo com recomendações de Werner et al. (1996). O plantio das gramíneas foi realizado em dezembro de 2000 com mudas enraizadas dispostas em sulco, com 0,50 $\mathrm{m}$ de espaçamento entre sulcos e $0,5 \mathrm{~m}$ entre plantas. Nos sulcos efetuou-se adubação de $100 \mathrm{~kg} / \mathrm{ha}$ de $\mathrm{P}_{2} \mathrm{O}_{5}$ e $30 \mathrm{~kg}$ de $\mathrm{K}_{2} \mathrm{O}$, na forma de superfosfato simples e cloreto de potássio, respectivamente. Em março de 2001, foi realizado o corte de uniformização, com segadeira-costal, na altura de $20 \mathrm{~cm}$ do solo para o capim-setária e a $10 \mathrm{~cm}$ para as demais espécies. Após o corte de uniformização, a cada 14 dias foram aplicados em cobertura $20 \%$ da dose total do adubo nitrogenado na forma de sulfato de amônio, nos cinco níveis, que corresponderam a 0,100,200,300 e $400 \mathrm{~kg}$ de N/ha. A adubação potássica, que também foi fracionada da mesma forma, consistiu de $60 \mathrm{~kg}$ de $\mathrm{K}_{2} \mathrm{O} / \mathrm{ha}$. As gramíneas foram irrigadas e os tratos culturais feitos mecanicamente sempre que necessário.

Os cortes para colheita das amostras foram feitos a 20 e $10 \mathrm{~cm}$ do solo para o capim-setária e as demais gramíneas, respectivamente. A área para colheita das amostras foi de $0,25 \mathrm{~m}^{2}$, localizada no centro da subsubparcela. Após o corte, as amostras foram pré-secas em estufa de ventilação forçada $\left(60 \pm 5^{\circ} \mathrm{C} / 72\right.$ horas $)$ e trituradas em moinho de facas com peneira de malha de $1 \mathrm{~mm}$.

As amostras foram analisadas quanto aos teores de matéria seca (MS), proteína bruta (PB), extrato etéreo (EE), matéria mineral (MM) e lignina em ácido sulfúrico 72\% p/p, segundo métodos descritos por Silva \& Queiroz (2002). As avaliações quanto aos teores de fibra insolúvel em detergente neutro (FDN) e fibra insolúvel em detergente ácido 
(FDA) seguiram os protocolos de Van Soest \& Robertson (1985) e Van Soest et al. (1991). Os carboidratos totais (CT) foram obtidos pela fórmula: $\mathrm{CT}=100-(\mathrm{PB}+\mathrm{EE}+\mathrm{MM})$ e os carboidratos não-fibrosos (CNF), pela subtração da fibra em detergente neutro corrigida para seu conteúdo de cinzas e proteína (FDNcp) dos carboidratos totais. A digestibilidade in vitro da matéria seca (DIVMS) foi estimada em estádio de 48 horas em inóculo ruminal (Tabelas 1 e 2), conforme descrito por Tilley \& Terry (1963).

As taxas de digestão dos CNF e dos carboidratos fibrosos (CF) foram estimadas pela técnica de produção de gases, conforme relatado por Pell \& Schofield (1993). As amostras foram incubadas em frascos com capacidade de $50 \mathrm{~mL}$, onde foram pesados aproximadamente $100 \mathrm{mg}$ de substrato, acrescidas de $8 \mathrm{~mL}$ de solução tampão de McDougall (pH 6,9-7,0) e 2 mL de inóculo ruminal e mantidas sob condições anaeróbicas a $39^{\circ} \mathrm{C}$. O animal doador do inóculo foi um bovino mestiço Holandês $\times$ Zebu alimentado exclusivamente com forragem verde. Os frascos foram fechados hermeticamente e os gases acumulados entre a tampa e a superfície do meio de cultura foram mensurados por meio de um transdutor acoplado a um multímetro. A pressão formada pelo acúmulo dos gases, que inicialmente foi medida em unidades elétricas $(\mathrm{mV})$, foi convertida posteriormente em volume de gás $(\mathrm{mL})$, de acordo com procedimento descrito por Pell \& Schofield (1993). As leituras de pressão foram realizadas nos seguintes tempos: 0, 1, 2, 3, 4, 5, 6, 8, 10, 12, 18, 24, 30, 36, 48, 60, 72, 96,120 e 144 horas. A cinética da produção cumulativa de gases foi analisada empregando-se o modelo logístico bicompartimental (Schofield et al., 1994):

$$
V t=V f_{1}\left\{1+\exp \left[2+4 \frac{\mu m_{1}}{V f_{1}}(L-t)\right]\right\}^{-1}+V f_{2}\left\{1+\exp \left[2+4 \frac{\mu m_{2}}{V f_{2}}(L-t)\right]\right\}^{-1}
$$

em que: $\mathrm{Vt}=$ volume acumulado do tempo $\mathrm{t}(\mathrm{mL}) ; \mathrm{Vf}=$ volume total de gases produzido em $\mathrm{t} \rightarrow \infty(\mathrm{mL}) ; \mu \mathrm{m}=$ taxa máxima de produção de gases $(\mathrm{mL} / \mathrm{h}) ; \mathrm{L}=$ latência $(\mathrm{h})$; $\mathrm{t}$ = tempo após o início da incubação (h); e "1" e "2" ( subescritos) = indicadores referentes à cinética de produção de gases a partir de carboidratos fibrosos e carboidratos não-fibrosos, respectivamente. A razão $\mu \mathrm{m} / \mathrm{V}$ f representa a taxa específica de digestão (k) do substrato (Schofield et al., 1994). Assim, assumiu-se que a fração de lenta digestão é representada pelos carboidratos fibrosos e a fração de rápida degradação, pelos carboidratos não-fibrosos.

O experimento foi instalado segundo um delineamento em blocos casualizados ( 3 blocos), em esquema de parcela sub-subdivididas, de modo que as gramíneas foram alocadas às parcelas, a adubação nitrogenada às subparcelas e as idades às subsubparcelas, segundo o modelo:

$$
\begin{gathered}
\mathrm{Y}_{\mathrm{ijkl}}=\mu+\mathrm{G}_{\mathrm{i}}+\mathrm{B}_{\mathrm{j}}+\mathrm{e}_{\mathrm{ij}}+\mathrm{N}_{\mathrm{k}}+\mathrm{GN}_{\mathrm{ik}}+\mathrm{E}_{\mathrm{ijk}}+\mathrm{C}_{1}+\mathrm{GC}_{\mathrm{il}}+ \\
\mathrm{NC}_{\mathrm{kl}}+\mathrm{GNC}_{\mathrm{ikl}}+\varepsilon_{\mathrm{ijkl}},
\end{gathered}
$$

em que: $\mathrm{Y}_{\mathrm{ijkl}}=$ observação geral relativa à gramínea $\mathrm{i}$, ao bloco $\mathrm{j}$, aos níveis de adubação $\mathrm{k}$ e às idades $1 ; \mu=$ constante geral; $\mathrm{G}_{\mathrm{i}}=$ efeito da gramínea $\mathrm{i}$, em que $\mathrm{i}=1,2,3 \mathrm{e} 4 ; \mathrm{B}_{\mathrm{j}}=$ efeito do bloco $\mathrm{j}$, em que $\mathrm{j}=1,2$ e 3 ; $\mathrm{e}_{\mathrm{ij}}=$ efeito residual das parcelas; $\mathrm{N}_{\mathrm{k}}=$ efeito de doses de adubação $\mathrm{k}$, em que $\mathrm{k}=1$, 2, 3, 4 e 5; $\mathrm{GN}_{\mathrm{ij}}=$ efeito da interação da gramínea i e a dose de adubação $\mathrm{k} ; \mathrm{E}_{\mathrm{ijk}}=$ efeito residual das subparcelas; $\mathrm{C}_{1}=$ efeito da idade de corte 1 , em que $1=1,2,3$ e $4 ; \mathrm{GC}_{\mathrm{il}}=$ efeito da interação gramínea $\mathrm{i} \times$ idade de corte $1 ; \mathrm{NC}_{\mathrm{kl}}=$ efeito da interação dose de adubação $\mathrm{k} \times$ idade de corte 1 ; $\mathrm{GNC}_{\mathrm{ikl}}=$ efeito da interação gramínea $\mathrm{i} \times$ dose de adubação $\mathrm{k} \times$ idade de corte $1 ; \varepsilon_{\mathrm{ijkl}}=$ erro aleatório, associado a cada observação, pressuposto NID $\left(0 ; \sigma^{2}\right)$.

Após as análises químicas e biológicas, os resultados foram reduzidos às médias de tratamentos (combinações dos níveis dos fatores alocados às parcelas, subparcelas e subsubparcelas), e analisados por intermédio de análise de fatores (factor analysis), empregando-se o método dos componentes principais para obtenção dos fatores e o método "Varimax" para rotação e ortogonalização de fatores. Adotaram-se como critérios de seleção de fatores as cargas fatoriais e a fração retida da variação total (comunalidade) (Johson \& Wichern, 1998).

\section{Resultados e Discussão}

A aplicação da análise de fatores tem como finalidade a descrição das relações de co-variância entre muitas variáveis com base em um pequeno número de quantidades aleatórias, não-observáveis, denominadas fatores (Johnson \& Wichern, 1998). Neste contexto, as variáveis são agrupadas por meio de suas correlações, ou seja, aquelas pertencentes a um mesmo grupo serão fortemente correlacionadas entre si, mas pouco correlacionadas às variáveis de outro grupo. Assim, cada grupo de variáveis será representado por um fator, responsável pelas correlações observadas.

Após a avaliação da variação conjunta total das variáveis, optou-se pela adoção de três fatores, que englobaram $86,4 \%$ da variação total, garantindo pequena perda da variação total entre tratamentos pela redução multivariada.

Os parâmetros cinéticos da produção cumulativa de gases expressos na Tabela 3 foram utilizados para gerar os escores fatoriais apresentados na Tabela 4, na qual se observa que as cargas fatoriais refletem diretamente a correlação entre o fator e cada uma das variáveis (Johnson 
Tabela 1 - Composição química das gramíneas em cada dose de adubação (kg N/ha) e idade de corte (dias)

\begin{tabular}{|c|c|c|c|c|c|c|c|c|c|c|c|c|c|c|c|c|c|c|c|c|c|}
\hline \multirow[t]{2}{*}{ Idade } & \multirow[t]{2}{*}{ Dose } & \multicolumn{5}{|c|}{ Capim-setária } & \multicolumn{5}{|c|}{ Capim-hemarthria } & \multicolumn{5}{|c|}{ Capim-angola } & \multicolumn{5}{|c|}{ Capim-acroceres } \\
\hline & & $\mathrm{MS}^{1}$ & $\mathrm{MM}^{2}$ & $\mathrm{EE}^{2}$ & $\mathrm{FDN}^{2}$ & $\mathrm{~PB}^{2}$ & $\mathrm{MS}^{1}$ & $\mathrm{MM}^{2}$ & $\mathrm{EE}^{2}$ & $\mathrm{FDN}^{2}$ & $\mathrm{~PB}^{2}$ & $\mathrm{MS}^{1}$ & $\mathrm{MM}^{2}$ & $\mathrm{EE}^{2}$ & $\mathrm{FDN}^{2}$ & $\mathrm{~PB}^{2}$ & $\mathrm{MS}^{1}$ & $\mathrm{MM}^{2}$ & $\mathrm{EE}^{2}$ & $\mathrm{FDN}^{2}$ & $\mathrm{~PB}^{2}$ \\
\hline \multirow{5}{*}{28} & 0 & 12,86 & 14,17 & 3,64 & 61,99 & 13,75 & 15,20 & 12,76 & 2,07 & 63,41 & 13,44 & 14,98 & 13,66 & 1,92 & 65,22 & 16,97 & 22,64 & 10,37 & 1,94 & 71,27 & 16,33 \\
\hline & 100 & 12,17 & 12,00 & 2,94 & 61,43 & 15,02 & 17,13 & 11,11 & 1,58 & 67,09 & 14,30 & 14,16 & 11,87 & 2,63 & 63,17 & 17,56 & 23,85 & 10,09 & 1,77 & 69,15 & 18,34 \\
\hline & 200 & 10,86 & 11,47 & 3,33 & 61,76 & 18,75 & 16,63 & 10,98 & 1,86 & 64,60 & 13,95 & 14,70 & 13,21 & 2,04 & 61,22 & 20,60 & 20,48 & 11,48 & 1,75 & 65,48 & 19,74 \\
\hline & 300 & 11,79 & 11,68 & 2,73 & 58,84 & 21,32 & 13,97 & 11,33 & 1,55 & 62,98 & 15,91 & 14,32 & 11,62 & 2,01 & 60,27 & 21,74 & 19,38 & 8,64 & 2,23 & 66,24 & 18,66 \\
\hline & 400 & 10,72 & 10,61 & 2,84 & 53,96 & 25,24 & 14,75 & 11,28 & 1,79 & 68,03 & 17,09 & 12,25 & 12,22 & 2,15 & 61,57 & 21,28 & 20,65 & 8,57 & 1,73 & 67,79 & 20,40 \\
\hline \multirow{7}{*}{42} & Média & 11,68 & 11,99 & 3,10 & 59,60 & 18,82 & 15,54 & 11,49 & 1,77 & 65,22 & 14,94 & 14,08 & 12,52 & 2,15 & 62,29 & 19,63 & 21,40 & 9,83 & 1,88 & 67,99 & 18,69 \\
\hline & 0 & 17,01 & 9,09 & 2,90 & 71,31 & 10,66 & 17,74 & 8,09 & 1,53 & 73,99 & 9,82 & 17,38 & 11,62 & 1,07 & 71,93 & 10,39 & 25,38 & 7,33 & 0,66 & 77,22 & 12,95 \\
\hline & 100 & 12,62 & 11,11 & 2,03 & 70,45 & 12,13 & 15,31 & 8,76 & 1,86 & 75,65 & 10,09 & 17,48 & 11,87 & 1,61 & 71,06 & 12,58 & 20,22 & 8,38 & 0,74 & 73,88 & 13,92 \\
\hline & 200 & 13,05 & 9,51 & 2,81 & 76,13 & 11,48 & 16,84 & 7,73 & 2,60 & 76,27 & 9,57 & 16,11 & 11,11 & 1,17 & 72,79 & 12,70 & 19,57 & 8,04 & 1,33 & 73,96 & 15,49 \\
\hline & 300 & 14,72 & 9,22 & 3,34 & 71,08 & 17,40 & 18,52 & 8,22 & 1,01 & 74,42 & 11,19 & 18,43 & 12,19 & 0,55 & 74,06 & 13,13 & 21,04 & 8,37 & 2,02 & 69,64 & 15,30 \\
\hline & 400 & 15,87 & 8,94 & 4,42 & 71,09 & 18,17 & 15,12 & 9,37 & 1,46 & 72,16 & 10,68 & 18,41 & 10,46 & 1,29 & 71,54 & 14,09 & 19,68 & 8,67 & 1,42 & 70,42 & 15,70 \\
\hline & Média & 14,65 & 9,57 & 3,10 & 72,01 & 13,97 & 16,71 & 8,43 & 1,69 & 74,50 & 10,27 & 17,56 & 11,45 & 1,14 & 72,28 & 12,58 & 21,18 & 8,16 & 1,23 & 73,02 & 14,67 \\
\hline \multirow{5}{*}{56} & 0 & 14,55 & 11,92 & 1,79 & 66,18 & 10,48 & 15,57 & 11,18 & 0,73 & 69,36 & 10,95 & 17,55 & 12,17 & 1,10 & 63,79 & 13,27 & 20,52 & 9,20 & 2,38 & 65,32 & 13,15 \\
\hline & 100 & 12,82 & 10,99 & 4,06 & 63,67 & 12,08 & 16,33 & 11,76 & 1,04 & 68,46 & 10,27 & 17,18 & 13,56 & 0,84 & 64,30 & 13,95 & 19,42 & 9,95 & 1,65 & 64,47 & 16,45 \\
\hline & 200 & 14,01 & 12,01 & 2,59 & 63,76 & 11,82 & 14,96 & 11,18 & 0,42 & 68,18 & 12,33 & 15,68 & 13,30 & 0,54 & 62,91 & 15,98 & 18,34 & 10,26 & 2,09 & 63,12 & 18,09 \\
\hline & 300 & 11,94 & 10,79 & 1,50 & 64,99 & 16,02 & 16,19 & 10,72 & 0,34 & 65,07 & 10,53 & 16,01 & 12,56 & 1,10 & 63,62 & 15,46 & 20,20 & 9,48 & 2,17 & 66,17 & 18,40 \\
\hline & 400 & 13,07 & 10,81 & 0,91 & 61,06 & 17,08 & 15,70 & 11,40 & 0,71 & 67,12 & 11,75 & 16,50 & 12,85 & 0,59 & 62,03 & 17,64 & 20,58 & 12,31 & 2,45 & 66,32 & 18,09 \\
\hline \multirow{7}{*}{70} & Média & 13,28 & 11,30 & 2,17 & 63,93 & 13,50 & 15,75 & 11,25 & 0,65 & 67,64 & 11,17 & 16,58 & 12,89 & 0,83 & 63,33 & 15,26 & 19,81 & 10,24 & 2,15 & 65,08 & 16,84 \\
\hline & 0 & 14,77 & 11,46 & 1,66 & 66,57 & 10,68 & 14,69 & 9,88 & 1,86 & 69,31 & 10,75 & 17,22 & 10,63 & 0,67 & 65,54 & 12,61 & 18,27 & 9,97 & 2,30 & 65,10 & 12,66 \\
\hline & 100 & 13,98 & 9,39 & 2,63 & 64,84 & 12,49 & 14,59 & 10,54 & 1,21 & 70,46 & 11,84 & 17,03 & 12,90 & 1,47 & 64,49 & 13,59 & 17,66 & 11,31 & 1,54 & 65,40 & 14,59 \\
\hline & 200 & 14,07 & 11,40 & 1,71 & 67,35 & 11,89 & 14,45 & 11,48 & 1,60 & 70,16 & 13,09 & 16,45 & 12,68 & 1,49 & 65,15 & 17,21 & 17,32 & 9,46 & 1,59 & 64,35 & 16,88 \\
\hline & 300 & 13,46 & 9,91 & 2,65 & 64,49 & 17,94 & 15,18 & 10,54 & 1,16 & 70,22 & 12,61 & 17,40 & 12,71 & 0,76 & 64,57 & 16,21 & 16,56 & 10,59 & 1,44 & 66,62 & 16,46 \\
\hline & 400 & 11,95 & 11,77 & 2,77 & 61,52 & 16,87 & 15,03 & 10,49 & 1,45 & 68,39 & 13,22 & 15,97 & 12,68 & 1,48 & 70,59 & 17,70 & 15,27 & 11,81 & 1,41 & 66,71 & 19,06 \\
\hline & Média & 13,65 & 10,79 & 2,28 & 64,95 & 13,97 & 14,79 & 10,59 & 1,46 & 69,71 & 12,30 & 16,81 & 12,32 & 1,17 & 66,07 & 15,46 & 17,02 & 10,63 & 1,66 & 65,64 & 15,93 \\
\hline
\end{tabular}

MS - matéria seca; MM - matéria mineral; EE - extrato etéreo; FDN - fibra em detergente neutro; PB - proteína bruta. 
Tabela 2 - Composição da parede celular (\% da MS) e digestibilidade in vitro da matéria seca (DIVMS - \%) das gramíneas em cada dose de adubação (kg N/ha) e idade de corte (dias) Capim-angola Capim-acroceres

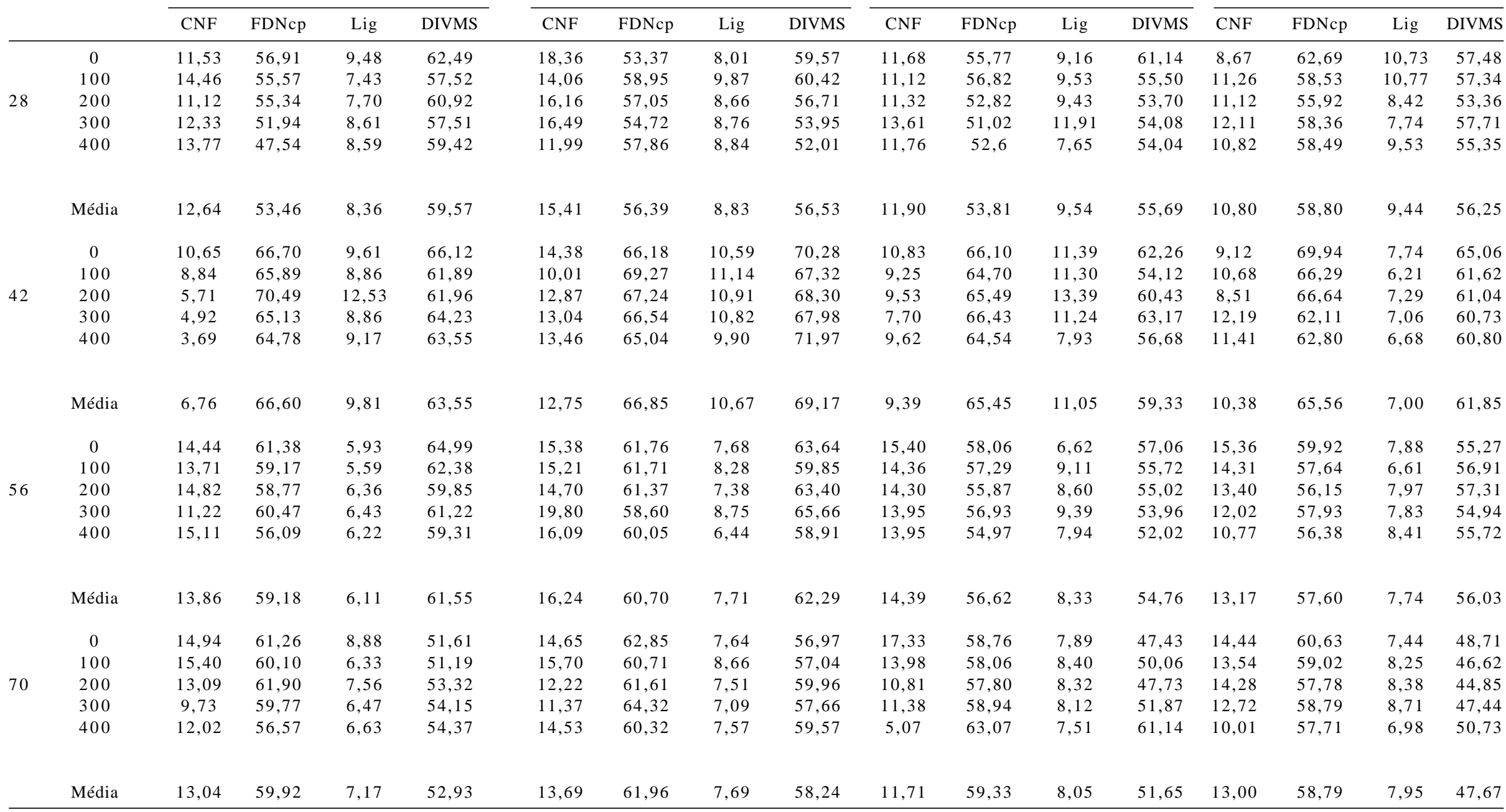

CNF - carboidratos não-fibrosos; FDNcp - fibra em detergente neutro isenta de cinza e proteína; Lig - lignina; DIVMS - digestibilidade in vitro da matéria seca 
\& Wichern, 1998). Desta forma, a avaliação do comportamento dos escores fatoriais (Tabela 4; Figuras 1, 2 e 3) reflete, indiretamente, o comportamento das variáveis fortemente associadas ao fator (elevadas cargas fatoriais).

Neste contexto, o fator 1 associou-se fortemente e de forma positiva ao volume de gás da fração de lenta digestão e à taxa de degradação da fração de rápida digestão $\left(\mathrm{Vf}_{1}, \mathrm{k}_{2}\right)$ e de forma negativa ao volume de gás da fração de rápida digestão $\left(\mathrm{Vf}_{2}\right)$ (Tabelas 3 e 4). $\mathrm{O}$ fator 2 associou-se fortemente de forma positiva com a taxa de degradação da fração de lenta digestão $\left(\mathrm{k}_{1}\right)$ e de forma negativa com a latência $(\mathrm{L})$. Por sua vez, o fator 3 associou-se à digestibilidade in vitro da matéria seca (DIVMS). Assume-se que a fração de lenta degradação representa a cinética de produção de gases a partir dos carboidratos fibrosos e a fração de rápida degradação, a dos carboidratos não-fibrosos.

$\mathrm{Na}$ avaliação da fração retida da variação total e do comportamento das cargas fatoriais, todas as variáveis avaliadas apresentaram elevada comunalidade (Tabela 4), que expressa a fração da variância de cada variável explicada pelos três fatores comuns adotados (Johnson \& Wichern, 1998).

As cargas fatoriais do fator 1 (Tabela 4; Figura 1) permitem evidenciar que, à medida que o volume de gás oriundo dos carboidratos fibrosos $\left(\mathrm{Vf}_{1}\right)$ se amplia, reduz-se proporcionalmente o volume de gás oriundo dos carboidratos não-fibrosos $\left(\mathrm{Vf}_{2}\right)$.

O fator 1 assumiu escores fatoriais maiores para os capins setária e hemarthria aos 28 dias, para angola e acroceres aos 70 dias, diferenças que podem estar associadas às características inerentes à estrutura da parede celular dessas gramíneas. Segundo Jung \& Allen (1995), embora todas as plantas tenham estrutura básica similar de parede celular, existem importantes diferenças quanto aos detalhes de composição e estrutura de parede. Estes mesmos autores citaram que as plantas não apresentam genes específicos para produção de fibra em detergente neutro (FDN) e fibra em detergente ácido (FDA), mas que esses componentes da planta representam grande proporção da parede celular e, indubitavelmente, estão fortemente correlacionados à atividade de genes para síntese de celulose, xilana e lignina. Como os gases produzidos a partir dos carboidratos fibrosos originam-se da FDNcp, estes resultados podem ser reflexo dos menores teores deste componente para estas gramíneas nestas idades (Tabela 2).

O efeito da adubação nitrogenada (Tabela 4) sobre os escores do fator 1 foi pequeno e inconsistente, o que comprova pouca influência da adubação nitrogenada sobre o volume de gás produzido a partir dos carboidratos fibrosos
$\left(\mathrm{Vf}_{1}\right)$ e não-fibrosos $\left(\mathrm{Vf}_{2}\right)$ e tampouco sobre a taxa de degradação destes carboidratos $\left(\mathrm{k}_{2}\right)$. Entre os capins, o que apresentou maiores escores médios do fator 1 foi o acroceres e o menor, o hemarthria.

Os escores fatoriais relacionados ao fator 2 assumiram maiores valores aos 42 dias de idade para todas as gramíneas e reduziram em idades mais avançadas (Tabela 4; Figura 2). Como é um processo determinado pela hidratação das partículas e saturação dos locais disponíveis para fixação microbiana, a latência é sucessivamente dependente da anatomia da planta e de fatores como mastigação, salivação (Jung \& Allen, 1995) e síntese de estruturas e enzimas microbianas. Embora a latência obtida pelo modelo de Schofield et al. (1994) seja de procedência mista, ou seja, comuns aos dois compartimentos de digestão, pode-se enfocar a fração fibrosa como diretamente associada à maior parte dos eventos envolvidos na latência. Esta associação permite observar que as maiores latências foram obtidas na mesma idade em que se obtiveram os maiores teores de lignina e FDNcp, com queda nas idades posteriores (Tabela 2). Henriques et al. (2007), ao avaliarem estas mesmas gramíneas quanto às suas frações de carboidratos, relataram que alterações nos mecanismos morfofisiológicos das plantas sugerem que, à medida que a idade da planta avança, ocorre redução das proporções de carboidratos potencialmente degradáveis, corroborando a elevação da latência e redução em $\mathrm{k}_{1}$ com a elevação da idade de corte além de 42 dias.

De forma semelhante à observada para o fator 1 , a adubação nitrogenada também apresentou efeito pequeno e inconsistente sobre os escores do fator 2, demonstrando pouca influência sobre a latência ou taxa de degradação da fração de carboidratos fibrosos, que assumiram valores médios de 10,9 horas e $0,013 \mathrm{~h}^{-1}$, respectivamente. Entre as gramíneas, a que apresentou maiores escores do fator 2 foi a setária e a menor, a acroceres.

Foram observados escores fatoriais associados ao fator 3 mais elevados aos 42 dias de idade para todas as gramíneas (Tabela 2; Figura 3), demonstrando que nesta idade se obtêm as maiores disponibilidades para degradação de matéria seca destas gramíneas. O fator 3 apresentou redução dos seus escores além dos 42 dias, fato que reflete a redução dos valores de DIVMS à medida que se elevou a idade de corte (Tabela 2), demonstrando, com base neste parâmetro, que esta idade é a mais recomendada para corte destas gramíneas.

O capim-hemarthria assumiu os maiores escores do Fator 3, pois apresentou a mais alta digestibilidade entre os capins testados (Figura 3). Embora o efeito da aduba- 
Tabela 3 - Volume de gás $(\mathrm{mL})$ da fração dos $\mathrm{CF}\left(\mathrm{Vf}_{1}\right)$, taxa de degradação $\left(\mathrm{h}^{-1}\right)$ da fração de carboidratos fibrosos $\left(\mathrm{k}_{1}\right)$, volume de gás da fração dos carboidratos não-fibrosos $\left(\mathrm{Vf}_{2}\right)$, taxa de degradação da fração de carboidratos não-fibrosos $\left(\mathrm{k}_{2}\right)$ e latência $(\mathrm{L})$ em cada dose de adubação (kg N/ha) e idade de corte (dias)

\begin{tabular}{|c|c|c|c|c|c|c|c|c|c|c|c|c|c|c|c|c|c|c|c|c|c|}
\hline \multirow[t]{2}{*}{ Idade } & \multirow{2}{*}{$\begin{array}{l}\text { Dose } \\
\mathrm{Vf}_{1}\end{array}$} & \multicolumn{5}{|c|}{ Capim-setária } & \multicolumn{5}{|c|}{ Capim-hemarthria } & \multicolumn{5}{|c|}{ Capim-angola } & \multicolumn{5}{|c|}{ Capim-acroceres } \\
\hline & & $\mathrm{K}_{1}$ & $\mathrm{Vf}_{2}$ & $\mathrm{~K}_{2}$ & $\mathrm{~L}$ & $\mathrm{Vf}_{1}$ & $\mathrm{~K}_{1}$ & $\mathrm{Vf}_{2}$ & $\mathrm{~K}_{2}$ & $\mathrm{~L}$ & $\mathrm{Vf}_{1}$ & $\mathrm{~K}_{1}$ & $\mathrm{Vf}_{2}$ & $\mathrm{~K}_{2}$ & $\mathrm{~L}$ & & $\mathrm{Vf}_{1}$ & $\mathrm{~K}_{1}$ & $\mathrm{Vf}_{2}$ & $\mathrm{~K}_{2}$ & $\mathrm{~L}$ \\
\hline \multirow{5}{*}{28} & 0 & 12,04 & 0,0138 & 8,43 & 0,0604 & 13,4 & 9,93 & 0,0152 & 10,96 & 0,0706 & 8,5 & 11,06 & 0,0115 & 5,59 & 0,1106 & 13,0 & 15,72 & 0,0131 & 5,41 & 0,0816 & 14,9 \\
\hline & 100 & 11,32 & 0,0153 & 10,43 & 0,0712 & 7,5 & 13,54 & 0,0118 & 6,41 & 0,0724 & 14,6 & 14,84 & 0,0123 & 6,04 & 0,0682 & 15,5 & 15,51 & 0,0121 & 5,37 & 0,0749 & 15,8 \\
\hline & 200 & 11,73 & 0,0141 & 8,44 & 0,0564 & 12,6 & 9,96 & 0,0141 & 13,59 & 0,0523 & 8,7 & 10,38 & 0,0101 & 5,30 & 0,1038 & 8,9 & 16,76 & 0,0131 & 4,55 & 0,0891 & 15,7 \\
\hline & 300 & 11,31 & 0,0144 & 8,50 & 0,0723 & 9,50 & 9,82 & 0,0144 & 9,01 & 0,0744 & 8,4 & 9,40 & 0,0104 & 5,61 & 0,0940 & 11,8 & 10,85 & 0,0125 & 6,19 & 0,0573 & 14,6 \\
\hline & 400 & 11,59 & 0,0136 & 7,61 & 0,0687 & 9,80 & 9,94 & 0,0132 & 10,38 & 0,0637 & 8,5 & 12,47 & 0,0118 & 4,53 & 0,0708 & 13,9 & 12,04 & 0,0132 & 3,13 & 0,1027 & 18,6 \\
\hline
\end{tabular}

Média $\quad 11,60 \quad 0,0142 \quad 8,68 \quad 0,0658 \quad 10,6$

$\begin{array}{lllllll}0 & 10,20 & 0,0153 & 11,91 & 0,0717 \quad 7,0\end{array}$ $100 \quad 10,610,0188 \quad 11,500,0879 \quad 6,2$ $200 \quad 10,00 \quad 0,0174 \quad 11,63 \quad 0,0732 \quad 6,7$ $\begin{array}{llllll}300 & 10,33 & 0,0184 & 11,63 & 0,0783 & 7,0\end{array}$ $400 \quad 9,07 \quad 0,016 \quad 11,99 \quad 0,0654 \quad 8,0$

Média $\quad 10,04 \quad 0,0172 \quad 11,73 \quad 0,0753 \quad 7,0$

$\begin{array}{llllll}0 & 10,83 & 0,0165 & 9,38 & 0,0707 & 8,2\end{array}$ $100 \quad 10,20 \quad 0,0162 \quad 10,20 \quad 0,0708 \quad 8,4$ $\begin{array}{llllll}200 & 10,28 & 0,0165 & 9,14 & 0,0704 & 9,0\end{array}$ $\begin{array}{llllll}300 & 10,01 & 0,0174 & 8,23 & 0,0710 & 9,2\end{array}$ $\begin{array}{llllll}400 & 10,22 & 0,0153 & 9,05 & 0,0658 & 10,0\end{array}$

Média $\quad 10,31 \quad 0,0164 \quad 9,20 \quad 0,0697 \quad 9,0$

$\begin{array}{lllll}12,93 & 0,0155 & 7,76 & 0,0683 & 8,8\end{array}$ $\begin{array}{lllll}12,46 & 0,0155 & 8,19 & 0,0756 & 7,7\end{array}$ $\begin{array}{llllll}11,19 & 0,0157 & 9,38 & 0,0696 & 8,2\end{array}$ $\begin{array}{llllll}11,22 & 0,015 & 8,70 & 0,0585 & 7,6\end{array}$ $\begin{array}{llllll}11,18 & 0,0144 & 8,76 & 0,0600 & 8,4\end{array}$

$\begin{array}{llllll}10,64 & 0,0137 & 10,07 & 0,0667 & 9,7\end{array}$

$\begin{array}{llllll}9,57 & 0,0139 & 10,43 & 0,0521 & 7,5\end{array}$ $\begin{array}{ccccc}10,42 & 0,0120 & 9,92 & 0,0458 & 5,9\end{array}$ $\begin{array}{llllll}12,25 & 0,0177 & 8,70 & 0,0564 & 9,3\end{array}$ $\begin{array}{llllll}9,90 & 0,0133 & 8,77 & 0,0477 & 7,8\end{array}$ $\begin{array}{lllll}9,29 & 0,0141 & 9,22 & 0,0523 & 7,2\end{array}$

$10,29 \quad 0,0142 \quad 9,41 \quad 0,0509 \quad 7,54$

$\begin{array}{lllll}10,26 & 0,0115 & 9,11 & 0,0456 & 12,6\end{array}$ $\begin{array}{llllll}8,95 & 0,0091 & 11,63 & 0,0372 & 11,3\end{array}$ $\begin{array}{llllll}9,09 & 0,0102 & 10,65 & 0,0422 & 13,0\end{array}$ $\begin{array}{llllll}8,42 & 0,0105 & 10,47 & 0,0367 & 13,2\end{array}$ $\begin{array}{llllll}9,19 & 0,0100 & 9,44 & 0,0342 & 9,6\end{array}$

$\begin{array}{lllll}9,18 & 0,0103 & 10,26 & 0,0392 & 11,9\end{array}$

$\begin{array}{lllll}12,04 & 0,0132 & 6,66 & 0,0436 & 10,7\end{array}$ $\begin{array}{llllll}9,80 & 0,0118 & 8,48 & 0,0431 & 11,2\end{array}$ $\begin{array}{llllll}9,53 & 0,0109 & 8,01 & 0,0421 & 13,1\end{array}$ $\begin{array}{llllll}10,25 & 0,0109 & 7,38 & 0,0408 & 11,5\end{array}$ $\begin{array}{llllll}8,97 & 0,0099 & 9,10 & 0,0410 & 11,1\end{array}$ $\begin{array}{lllll}11,63 & 0,0112 & 5,41 & 0,0895 & 12,6\end{array}$

$\begin{array}{lllll}10,48 & 0,0141 & 8,30 & 0,1106 & 13,0\end{array}$ $\begin{array}{llllll}8,15 & 0,0136 & 8,31 & 0,0682 & 15,5\end{array}$ $8,16 \quad 0,0130 \quad 7,76 \quad 0,1038 \quad 8,9$ $\begin{array}{llllll}9,40 & 0,0124 & 7,11 & 0,0940 & 11,8\end{array}$ $\begin{array}{lllll}7,96 & 0,0121 & 8,17 & 0,0708 & 13,9\end{array}$

$\begin{array}{llllll}8,83 & 0,0130 & 7,930 & 0,0895 & 12,6\end{array}$

$\begin{array}{lllll}11,12 & 0,0122 & 5,21 & 0,0701 & 13,3\end{array}$ $\begin{array}{llllll}10,53 & 0,0122 & 5,64 & 0,0560 & 12,0\end{array}$ $\begin{array}{lllll}10,62 & 0,0128 & 5,88 & 0,0612 & 15,5\end{array}$ $\begin{array}{lllll}10,41 & 0,0122 & 5,59 & 0,0613 & 13,6\end{array}$ $\begin{array}{lllll}10,65 & 0,0108 & 5,94 & 0,0522 & 14,0\end{array}$

$\begin{array}{lllll}10,68 & 0,0120 & 5,45 & 0,0602 & 13,7\end{array}$

$\begin{array}{lllll}13,38 & 0,0123 & 5,73 & 0,0610 & 13,0\end{array}$ $\begin{array}{lllll}16,24 & 0,0134 & 3,77 & 0,0967 & 15,9\end{array}$ $\begin{array}{llllll}16,33 & 0,0133 & 4,20 & 0,0937 & 12,6\end{array}$ $\begin{array}{llllll}14,81 & 0,0131 & 4,15 & 0,0806 & 15,2\end{array}$ $\begin{array}{llllll}13,55 & 0,0142 & 1,98 & 0,0679 & 11,0\end{array}$
$14,18 \quad 0,0128 \quad 4,93 \quad 0,0811 \quad 15,9$

$\begin{array}{lllll}19,29 & 0,0133 & 4,34 & 0,0909 & 11,5\end{array}$ $\begin{array}{llllll}15,39 & 0,0132 & 5,96 & 0,0728 & 10,8\end{array}$ $\begin{array}{llllll}15,53 & 0,0136 & 5,72 & 0,0833 & 10,5\end{array}$ $\begin{array}{llllll}13,80 & 0,0130 & 7,30 & 0,0610 & 10,4\end{array}$ $\begin{array}{llllll}13,68 & 0,0134 & 6,48 & 0,0686 & 11,3\end{array}$

$\begin{array}{lllll}15,54 & 0,0133 & 5,96 & 0,0753 & 10,9\end{array}$ $\begin{array}{llllll}14,69 & 0,0134 & 5,29 & 0,0863 & 16,1\end{array}$ $\begin{array}{llllll}14,91 & 0,0133 & 5,03 & 0,0936 & 13,0\end{array}$ $\begin{array}{llllll}15,70 & 0,0134 & 6,54 & 0,0856 & 12,3\end{array}$ $\begin{array}{llllll}14,08 & 0,0132 & 4,09 & 0,1022 & 14,8\end{array}$ $\begin{array}{llllll}13,60 & 0,0129 & 4,59 & 0,1004 & 14,7\end{array}$

$14,60 \quad 0,0132 \quad 5,11 \quad 0,0936 \quad 14,2$

$\begin{array}{lllll}17,04 & 0,0136 & 4,29 & 0,1035 & 13,8\end{array}$ $\begin{array}{llllll}14,28 & 0,0131 & 5,23 & 0,0682 & 12,8\end{array}$ $\begin{array}{llllll}15,88 & 0,0135 & 5,80 & 0,0788 & 13,3\end{array}$ $\begin{array}{llllll}13,60 & 0,0122 & 5,17 & 0,0873 & 13,2\end{array}$ $\begin{array}{llllll}13,56 & 0,0106 & 5,46 & 0,0637 & 12,4\end{array}$

$14,87 \quad 0,0126 \quad 5,19 \quad 0,0803 \quad 13,1$ 
Tabela 4 - Escores fatoriais para os fatores associados aos volumes de gases e às taxas de degradação das gramíneas nas diferentes doses de adubação (kg N/ha) e idades de corte (dias) Idade Dose Capim-hemarthria Capim-acroceres

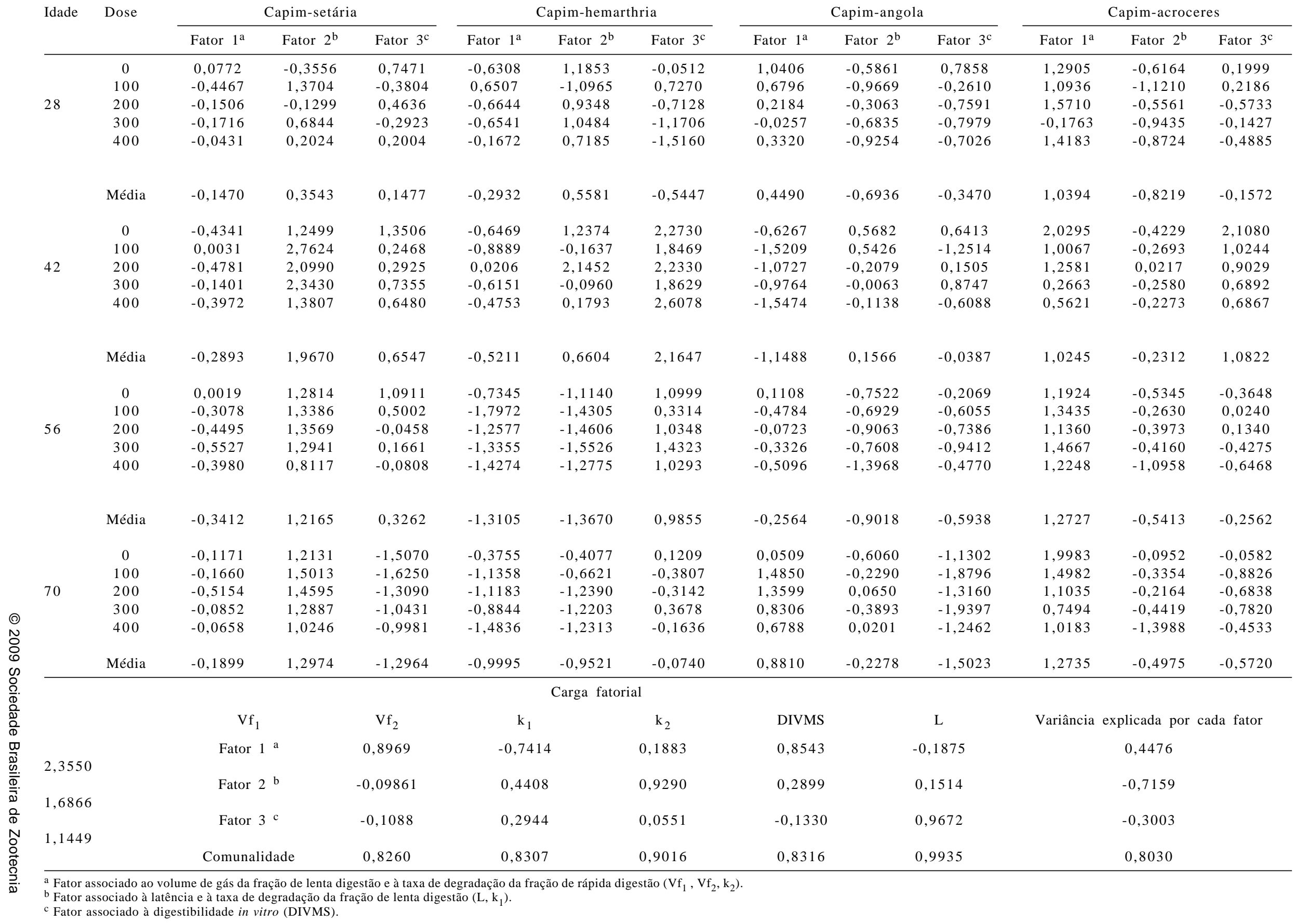




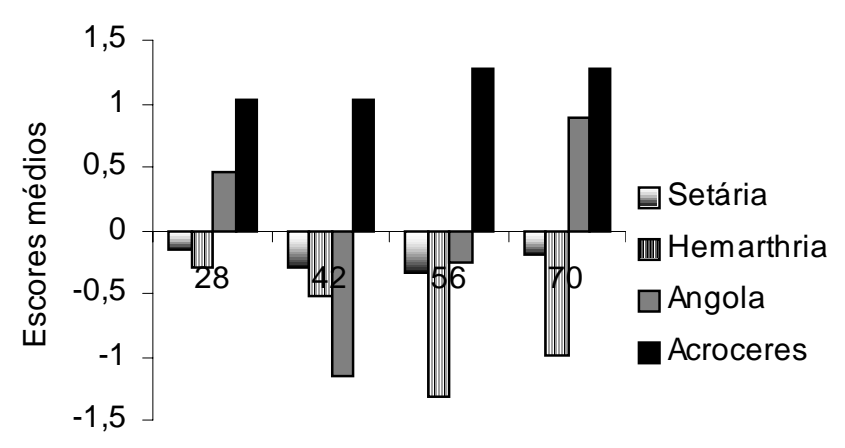

Idades de corte

Figura 1 - Comportamento médio (escores fatoriais) do fator associado ao volume de gás da fração de lenta digestão e à taxa de degradação da fração dos carboidratos nãofibrosos, quando avaliadas as gramíneas nas diferentes idades de corte (Fator 1).

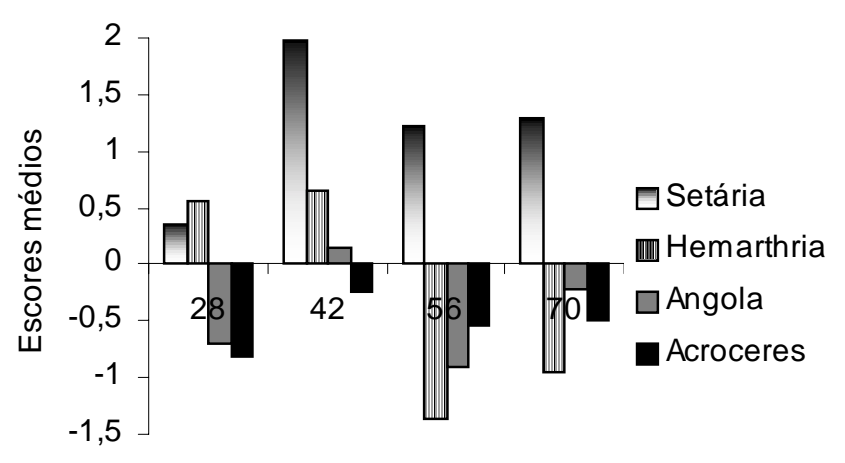

Idades de corte

Figura 2 - Comportamento médio (escores fatoriais) do fator associado à latência e à taxa de degradação dos carboidratos fibrosos de gramíneas em diversas idades de corte (Fator 2).

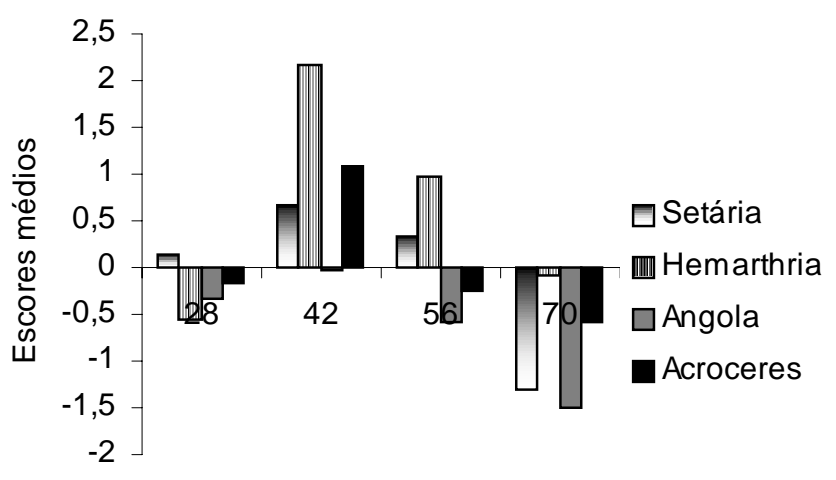

Idades de corte

Figura 3 - Comportamento médio (escores fatoriais) do fator associado à digestibilidade in vitro da matéria seca das gramíneas nas diferentes idades de corte (fator 3 ). ção nitrogenada tenha apresentado baixa significância, respostas mais positivas referentes a este parâmetro foram obtidas com a dose de $200 \mathrm{~kg}$ de N/ha.

Respostas sobre as variações da digestibilidade são reportadas por autores como associadas às variações na composição da parede celular (Jung \& Allen, 1995; Akin, 1989), que podem estar relacionadas às características morfogênicas. O crescimento e desenvolvimento da parede celular das plantas podem ser divididos em fases, de modo que primeiramente ocorre o desenvolvimento da parede primária com alongamento celular e concomitante deposição de pectina, xilanas e celulose. Posteriormente, quando o alongamento celular cessa, ocorre o espessamento da parede secundária, fase na qual a lignina passa a ser depositada mais intensamente.

A lignina tem sido descrita como polímeros de fenilpropanol depositados na parede celular, e sua composição e concentração podem afetar a taxa de digestão da fibra (Jung \& Allen, 1995). Segundo estes autores, a lignina associa-se muito pouco às células do mesófilo, em contraste com as do esclerênquima, que podem apresentar grande concentração deste composto. Anatomicamente, as células do mesófilo e as do floema são digeridas rapidamente, as da epiderme e da bainha parenquimática dos feixes são digeridas mais lenta e parcialmente e as do esclerênquima e do xilema, que apresentam parede celular espessa e lignificada, são muito pouco digeridas. Segundo Paciullo et al. (2002), o aumento da idade das gramíneas promove alterações nas proporções dos tecidos anatômicos das plantas, uma vez que a proporção de esclerênquima e xilema aumenta e a de mesófilo diminui. Além disso, Fukushima \& Savioli (2001) relataram que a passagem do início da fase reprodutiva para a fase de plena frutificação em gramíneas tropicais incorre alterações químicas nos constituintes da parede celular e, apesar da forte correlação negativa entre quantidade de lignina e digestibilidade, a composição química da lignina deve também ter importante papel na digestibilidade da parede celular.

\section{Conclusões}

Os parâmetros da cinética de degradação ruminal dos carboidratos das forrageiras foram influenciados pelas idades de corte. $\mathrm{O}$ avanço da idade das plantas após os 42 dias ocasionou redução da digestibilidade in vitro da matéria seca e das taxas de degradação das frações fibrosas e nãofibrosas, portanto, considerando esse parâmetro, esta idade é a mais recomendável para o corte destas gramíneas. A adubação nitrogenada não teve efeito evidente sobre as variáveis avaliadas, embora a dose de $200 \mathrm{~kg} / \mathrm{ha}$ tenha 
apresentado, de forma geral, influência mais positiva sobre os parâmetros avaliados. O capim-hemarthria se destacou dos demais por sua maior digestibilidade.

\section{Literatura Citada}

AKIN, D.E. Histological and physical factors affecting digestibility of forages. Agronomy Journal, v.81, p.17-25, 1989.

FUKUSHIMA, R.S.; SAVIOLI, N.M.F. Correlação entre digestibilidade in vitro da parede celular e três métodos analíticos para avaliação quantitativa da lignina. Revista Brasileira de Zootecnia, v.30, p.302-309, 2001.

HENRIQUES, L.T.; COELHO DA SILVA, J.F.; DETMANN, E. et al. Frações dos carboidratos de quatro gramíneas tropicais em diferentes idades de corte e doses de adubação nitrogenada. Arquivo Brasileiro Medicina Veterinária e Zootecnia, v.59, n.3, p.730-739, 2007.

JOHNSON, R.A.; WICHERN, D.W. Applied multivariate statistical analysis. 4.ed. New Jersey: Prentice-Hall, 1998. 816p.

JUNG, H.G.; ALLEN, M.S. Characteristics of plant cell walls affecting intake and digestibility of forages by ruminants. Journal of Animal Science, v.73, p.2774-2790, 1995.

MALAFAIA, P.A.M.; VALADARES FILHO, S.C.; VIEIRA, R.A.M. et al. Cinética ruminal de alguns alimentos investigada por técnicas gravimétricas e metabólicas. Revista Brasileira de Zootecnia, v.27, p.370-380, 1998.

MOTT, G.O.; MOORE, J.E. Forage evaluation in perspective. In: BARNES, R.F.; CLANTON, D.C.; GORDON, H. et al. (Eds.). Forage quality evaluation and utilization. Lincoln: Nebraska University, 1969. p.7-51.

PACIULlO, D.S.C.; GOMIDE, J.A.; SILVA, E.A.M. et al. Características anatômicas da lâmina foliar e do colmo de gramíneas forrageiras tropicais, em função do nível de inserção no perfilho, da idade e da estação de crescimento. Revista Brasileira de Zootecnia, v.31, p.890-899, 2002.
PELL, A.N.; SCHOFIELD, P. Computerized monitoring of gas production to measure forage digestion in vitro. Journal of Dairy Science, v.76, p.1063-1073, 1993.

PINTO, J.C.; GOMIDE, J.A.; MAESTRI, M. Produção de matéria seca e relação folha/caule de gramíneas forrageiras tropicais, cultivadas em vasos, com duas doses de nitrogênio. Revista Brasileira de Zootecnia, v.23, p.313-326, 1994.

SCHOFIELD, P.; PELL, A.N. Measurement and kinetics analysis of the neutral detergent-soluble carbohydrates fraction of legumes and grasses. Journal of Animal Science, v.73, p.3455-3463, 1995.

SCHOFIELD, P.; PITT, R.E.; PELL, A.N. Kinects of fiber digestion from in vitro gas production. Journal of Animal Science, v.72, p.2980-2991, 1994.

SILVA, D.J.; QUEIROZ, A.C. Análises de alimentos. Métodos químicos e biológicos. 3.ed. Viçosa, MG: Editora UFV, 2002. 235p.

SILVA, M.M.P. Características produtivas, morfogênicas e composição químico-bromatológica de gramíneas forrageiras tropicais, submetidas a diferentes condições hídricas do solo. 2003. 131f. Tese (Doutorado em Produção Animal) Universidade Estadual do Norte Fluminense, Campos dos Goytacazes, 2003.

TILLEY, J.M.A.; TERRY, R.A. A two-stage technique for the in vitro digestion of forage crops. Journal of British Grassland Society, v.18, p.104-111, 1963.

Van SOEST, P.J.; ROBERTSON, J.B. Analysis of forages and fibrous foods. Ithaca: Cornell University, 1985. 202p.

Van SOEST, P.J.; ROBERTSON, J.B.; LEWIS, B.A. Methods for dietary fiber, neutral detergent fiber, and nonstarch polysaccharides in relation to animal nutrition. Journal of Dairy Science, v.74, p.3583-3597, 1991

WILLIAMS, B.A. Cumulative gas-production techniques for forage evaluation. In: GIVENS, D.I.; OWEN, E.; AXFORD, R.F.E. et al. (Eds.) Forage evaluation in ruminant nutrition. The Netherlands: CAB International, 2000. p.189-213.

WERNER, J.C.; PAULINO, V.T.; CANTARELLA, H. et al. Recomendações de adubação e calagem para o Estado de São Paulo. 2.ed. Campinas: Instituto Agronômico de Campinas, 1996. p.263-273 